\title{
STUDIA NAD DOMIESZKĄ MINERALNĄ W CERAMICE NACZYNIOWEJ KULTURY AMFOR KULISTYCH Z TERENU KUJAW
}

\author{
THE STUDIES ON THE MINERAL ADMIXTURE \\ IN THE CERAMIC VESSELS OF THE GLOBULAR AMPHORA \\ CULTURE FROM THE KUYAVIA REGION
}

\author{
Anna Maria Świerczyńska \\ Wydział Archeologii, Uniwersytet im. Adama Mickiewicza \\ ul. Uniwersytetu Poznańskiego 7, 61-614 Poznań \\ annaswierczynska@wp.eu
}

\begin{abstract}
This article relates to the question, ,what exactly is a mineral admixture in Globular Amphora Culture?". My studies prove that only the granites fulfill the criteria. I designed the experiment. One of the goals was to examine which stone is the easiest to process. It was a rapakivi granite. Its minerals are pink or grey after processing. The admixture found in GAC ceramics has the same color and the same size of minerals. There was another type of admixture which was not recognizable.
\end{abstract}

KEY WORDS: Globular Amphora Culture, granite admixture, Kuyavia region

W niniejszych rozważaniach postawiłam sobie za cel rekonstrukcję, na poziomie analityczno-aplikacyjnym, procesu wytwarzania domieszki mineralnej, stosowanej w neolitycznym garncarstwie przez ludność kultury amfor kulistych (KAK) na Kujawach. Informacje zawarte w literaturze przedmiotu wskazywały, że jedynie skały z rodziny granitów mają odpowiedniej wielkości ziarna, stopień skrystalizowania i skład mineralny, który plasuje je w roli domieszki. Ta wiedza umożliwiła zaprojektowanie eksperymentu, który miał na celu odpowiedź w kwestii preferencji dotyczących doboru rodzaju granitu, jako podstawowego źródła uzyskiwania domieszki mineralnej. Pierwotnie zaplanowano w nim również badania mikroskopowe metodą płytek cienkich próbek (tzw. szlifów ceramicznych) wydzielonej ceramiki 
naczyniowej KAK, zawierającej ten rodzaj domieszki. Jednak ostatecznie, z przyczyn niezależnych, oparłam się na wynikach badań makroskopowych, które w rezultacie okazały się interesujące. Zastosowałam podział technologiczny, którego historia i zasady zostaną zarysowane poniżej. Uwzględniłam również charakterystykę stanowisk archeologicznych, z których został mi udostępniony materiał ceramiczny oraz częściowo kontekst tych stanowisk. Dla części z nich przeprowadziłam badania mikroskopowe i właśnie z tego względu zdecydowałam się je szerzej omówić. Aby pokazać dobitniej celowość stosowania granitów jako domieszki schudzającej, przytoczyłam także przykłady kilku innych stanowisk i uzyskane wyniki zastosowania do badań ceramiki metody szlifów cienkich ${ }^{1}$.

W tym celu również przybliżę pochodzenie eratyków fennoskandzkich oraz omówię właściwości skał narzutowych z rodziny granitów. Dla uproszczenia będę je nazywać „granitami”, ponieważ nie spotkałam się w pracach dotyczących neolitu Z wyróżnianiem poszczególnych ich rodzajów.

W środowisku naturalnym ${ }^{2}$ występuje znacznie więcej odmian granitów niż wytworów kulturowych z tej skały. Ze względu na swoje właściwości techniczne nie mógł być stosowany do wyrobu wszystkich typów narzędzi. Obserwujemy równocześnie popularne i intencjonalne jego użytkowanie, po uprzednim rozdrobnieniu, jako domieszki schudzającej do wyrobu ceramiki. Można na tej podstawie wysunąć hipotezę, że to właśnie z eratyków pozyskiwano tę domieszkę. Być może przygotowując domieszkę, stosowano pozostałości po wytwarzaniu narzędzi metodą przekształcenia morfometrycznego, która była popularna w tym czasie (Chachlikowski, 1990, s. 223-255, 262-265). Tej hipotezie sprzyja niska frekwencja małych odpadów poprodukcyjnych (Chachlikowski, 1990, s. 240).

Istotne jest również spostrzeżenie, że ludność KAK na Kujawach od pojawienia się, czyli fazy I do końca fazy IIIa, funkcjonowała obok kultury pucharów lejkowatych (KPL; Szmyt, 2013, ryc. 1.33). Stanowiska tych społeczności położone są blisko siebie, a częstokroć nawet się zazębiają ${ }^{3}$. Jednak na terenie Kujaw tylko w ramach KAK do wyrobu ceramiki użytkowano dużych ilości domieszki granitowej, co stanowi swoisty fenomen. W produkcji naczyń glinianych ludność KPL stosowała odmienne schudzające wypełnienie masy ceramicznej (Czebreszuk, 1996, s. 22-24). Trudno odpowiedzieć na pytanie, z czego wynikały te różnice. Niektórzy archeolodzy uważają, że granitowa domieszka w naczyniu zwiększa jego wytrzymałość, ogranicza kurczenie się przy suszeniu i pozwala budować większe naczynia. Tłumaczą jej obecność względami wyłącznie użytkowymi. Należy wspomnieć w tym miejscu, że niektóre rodzaje granitu są bardzo atrakcyjne wizualnie, w szczególności granit rapa-

\footnotetext{
${ }^{1}$ Artykuł stanowi skróconą i poprawioną wersję pracy dyplomowej (Świerczyńska, 2018), która nie była dotąd publikowana.

2 Dla stanowiska Goszczewo 13-procentowy udział liczbowy granitów w całym zbiorze wyniósł 51,57\% (Chachlikowski, 1994, tab. 8).

${ }^{3} \mathrm{Na}$ większości stanowisk, które opisuję w dalszej części artykułu pozostałości kultury amfor kulistych, wystąpiły w kontekście zabytków kultury pucharów lejkowatych.
} 
kiwi ${ }^{4}$. Trudno jednak thumaczyć, np. względami estetycznymi, ów „mały przewrót” w obrębie KAK w wytwórstwie ceramiki. Tym bardziej nie można z góry zakładać, że miał jakieś znaczenie ideologiczne. W odniesieniu do kultur pradziejowych uważa się, że wszystkie te elementy: technologia, kwestie społeczne i ideologiczne były $\mathrm{z}$ sobą zespolone, nierozerwalne. $\mathrm{W}$ związku z tym nie można jakiejkolwiek wytwórczości ujmować wyłącznie w kategoriach użyteczności. Jednak wymagałoby to zagadnienie osobnych studiów.

W związku z zakładanym celem tego artykułu przyjrzyjmy się dokładniej domieszce tłuczonych, rozdrabnianych granitów w naczyniach KAK. Zaczyna być stosowana od fazy IIa tej kultury (w fazie I wykorzystywano domieszkę podobną do tej używanej przez społeczności KPL). Wyraźna tendencja dodawania okruchów granitu do gliny w procesie wyrobu ceramiki dotyczy tzw. klasycznej fazy w rozwoju kujawskich ugrupowań ludności KAK. Właśnie Kujawy są pod tym kątem stosunkowo dobrze zbadane ${ }^{5}$. Na podstawie studiów nad ceramiką $\mathrm{z}$ tych terenów stworzono też system podziału i opisu technologicznego wytworów. Dzięki niemu można podzielić materiał chronologicznie, ponieważ poszczególne grupy i podgrupy technologiczne są typowe dla różnych faz rozwoju KAK (Szmyt, 1996, s. 26-27). Tłuczony granit był używany jako domieszka schudzająca już w fazie I, ale współwystępował z piaskiem. Dopiero w fazie IIa popularność tej technologii wyraźnie wzrasta i wynosi powyżej $60 \%$. Natomiast $w$ fazie IIb ceramika $z$ dodatkiem pokruszonych skał granitowych zaczęła zdecydowanie dominować nad innymi. Ta tendencja utrzymuje się w fazie IIIa, a w fazie IIIb traci nieco na popularności (Szmyt, 1996, s. 34-35). Wyraźnie widać, że domieszka rozdrobnionych granitów jest typowa przede wszystkim dla tzw. horyzontu klasycznoamforowego, obejmującego fazy IIb i IIIa KAK (Szmyt, 1996, s. 78).

\section{POCHODZENIE MATERIALU ERATYCZNEGO, W TYM GRANITÓW, NA KUJAWACH}

Przystępując do tego zagadnienia pod kątem archeologii, często korzystamy z wyników uzyskanych przez geologów i petrografów. Jednak ich standardowe postępowanie badawcze znacznie się różni, na co niektórzy badacze nie zwracają większej uwagi. Archeolog nakierowany jest na wytwórczość ludzi pradziejowych, a nie na strukturę geologiczną skał. Ze względu na odmienny cel stosowane są inne metody i zadawane odmienne pytania badawcze (Chachlikowski, 2013, s. 11-13). Do zupelnie innej kategorii można zaliczyć dzisiejszy obserwowany na powierzchni materiał

${ }^{4}$ Granit rapakiwi ma strukturę porfirowatą. Składa się z grubych ziaren minerałów, m.in. skaleni potasowych, które nadają mu intensywnie czerwony kolor, co czyni je atrakcyjnymi nawet obecnie. $\mathrm{Na}$ terenie Kujaw dostępny jego rodzaj pochodzący z Wysp Alandzkich, przyniesiony przez masy lądolodu (Czekalska, Kunkel, 1977, s. 97).

${ }^{5} \mathrm{~Np}$. badania prowadzone przez Zespół Badań Kujaw Instytutu Prahistorii UAM (Cofta-Broniewska, 1990, s. 5). 
eratyczny, który różni się od tego występującego w epoce neolitu. Brak wiedzy o tym prowadzi do nieuprawnionych wniosków. Geolodzy w swoich dociekaniach szukali obszarów macierzystych, na których materiał kamienny został włączony w obręb lądolodu. Najczęściej posługiwano się przy tym różnymi wariantami określania skał przewodnich (Górska, 2000, s. 9-17). Natomiast postępowanie archeologiczne jest nakierowane na zbadanie samej struktury dostępnego materiału litycznego, metod pozyskiwania i jego obróbki (Prinke, Skoczylas, 1980, s. 9). Ma to na celu określenie dostępności wybranych gatunków skał dla społeczności pradziejowych. Na tej podstawie można określić trendy w ich użytkowaniu oraz udział importów ${ }^{6}$. Podstawowe środki do uzyskania takich wyników to ocena makroskopowa, mikroskopowa i mikroskopowa płytek cienkich.

Nie powinno się również pomijać genezy utworów polodowcowych, w ramach których materiał eratyczny został zdeponowany. Procesy peryglacjalne, zachodzące w zasięgu działania lądolodu, oraz procesy eoliczne spowodowały ukształtowanie się rozległych terenów pokrytych piaskami lub lessami, także wydm śródlądowych, np. w obrębie dzisiejszej Puszczy Kampinoskiej (Czubla, Papińska, 2006, s. 144). Najbardziej charakterystycznymi tworami polodowcowymi są moreny składające się z materiału skalnego transportowanego przez lodowiec, który włączał go w swój obręb po drodze, a następnie pozostawiał na danym terenie. W ten sposób na powierzchnię Polski trafiło mnóstwo materiału skalnego z terenu dzisiejszej Skandynawii oraz Bałtyku. Gdy lądolód przez dłuższy czas pozostawał w jednym miejscu, wówczas w jego przedniej części powstawała morena czołowa, tworząc przy czole lodowca spiętrzony lub pofałdowany wał. Twór ten jest wyniesiony ponad poziom otaczającego terenu i ma wydłużony kształt odpowiadający czołu lądolodu. Moreny denne tworzyły się z materiału wleczonego przez lądolód w jego strefie spągowej. Lodowce, przemieszczając się, zdzierały lub żłobiły materiał podłoża. Mogły ciągnąć bloki skalne nawet kilometrowej długości. Przemieszczany w ten sposób materiał w czasie ruchu, poddawany dużym naciskom, ulegał przekształceniu. Powstały rumosz skalny podlegał też porysowaniu lub wygładzeniu (Marcinek, 1991, s. 79-80). Wody wypływające z lądolodu na skutek jego topnienia $\mathrm{w}$ cieplejszych okresach zabierały ze sobą drobniejszy materiał skalny, taki jak żwiry, piaski, mułki oraz małe kamienie. Wypływając z lądolodu, materiał ten niekiedy tworzył na jego przedpolu sandry (Marcinek, 1991, s. 81). Tworzywem moren jest głównie glina morenowa, zwana też zwałową. Obejmuje różne frakcje skalne, głównie iły, piasek, żwir, a czasami kamienie, a nawet większe odłamy skalne. Zazwyczaj osady lodowcowe występują warstwowo, ze względu na następujące naprzemiennie glacjały i interglacjały (Galon, 1972, s. 41). Gliny morenowe charakteryzują się znacznym zróżnicowaniem walorów fizycznych i składu tworzącego je materiału skalnego. Występujące w Polsce są zazwyczaj czerwono-brunatne bądź żółto-brunatne. Pod względem frakcji najwięcej, bo około połowy (ok. 50\%) masy glin morenowych, stanowią piaski,

\footnotetext{
${ }^{6}$ Importami najogólniej określa się przedmioty sprowadzone spoza terenu użytkowania lub z niedostępnego na miejscu, pozyskanego przez wymianę surowca. W tym przypadku można brać pod uwagę oba warianty.
} 
szacunkowo $25-40 \%$ - iły, ponadto ok. 10\% - mułki i 5\% - żwiry. Ilość narzutniaków nie jest ujednolicona. Wyróżnia się ok. 200 północnoeuropejskich polodowcowych skał przewodnich. Spośród skał krystalicznych w glinie morenowej w Polsce najwięcej jest granitów, mniej zaś porfirów bałtyckich, a także diabazów i bazaltów (Galon, 1972, s. 42).

Dla moich rozważań dotyczących domieszki schudzającej istotne są granity i na nich się skupię. Skład i właściwości skał określanych jako granity mogą znacznie różnić się od siebie. Ten stan rzeczy wynika ze zróżnicowania w obrębie składu mineralnego i ziarnistości. Mianem granitów określa się skały drobno-, średnio- i gruboziarniste ${ }^{7}$. Należą one zarówno do grupy skał magmowych, jak i metamorficznych, bowiem po wykrystalizowaniu się z magmy uległy przeobrażeniom w wyniku oddziaływania wysokiej temperatury i ciśnienia. Częściej wymienia się je jednak w tej pierwszej kategorii. Granity zaliczają się do skał kwaśnych, ziarnistych i plutonicznych (głębinowych). Skały należące do tej rodziny zawierają duże ilości krzemionki, nawet do $80 \%$. Mają strukturę porfirową. Pod względem chemicznym charakterystyczna jest przewaga alkaliów nad wapniem (Czekalska, Kunkel, 1977, s. 78). Do rodziny granitów należą: granit alkaliczny (zwany typowym), granit wapniowo-alkaliczny, granodioryt, granit muskowitowy, granulity i grajzeny. Polskie granity narzutowe wykształciły się w okresie prekambryjskim (Czekalska, Kunkel, 1977, s. 79).

Do precyzyjnego określenia rodzajów użytych granitów do produkcji ceramiki naczyniowej stosowane są metody makro- i mikroskopowe i to one pozwalają odpowiedzieć na wiele pytań dotyczących procesu wytwarzania ceramiki.

\section{MIKROSKOPOWE METODY ANALIZY CERAMIKI NACZYNIOWEJ - SZLIFY CIENKIE}

Dla wyselekcjonowanych materiałów ceramicznych pochodzących ze stanowisk archeologicznych z terenu Kujaw wykonano badania petrograficzne. Dla orientacji i tylko w skrócie przytoczę zasady takich badań. W pierwszej kolejności należy oddzielić część badanego przedmiotu, aby uzyskać świeży przełam. Następnie pozyskuje się fragment niewielkiej grubości, który później jest szlifowany do grubości $30 \mu \mathrm{m}$. Taką próbkę umieszcza się na szkiełku podstawowym i nakłada się na całość szkiełko nakrywkowe. Tak przygotowany preparat można badać pod mikroskopem polaryzacyjnym. Istnieją dwa różne sposoby oświetlenia, które może być do nich użyte: liniowe światło spolaryzowane (PPL) i dwułomne polaryzujące (XP). W dalszej kolejności następuje etap obserwacji próbki i interpretacji uzyskanych wyników. Duża część nowoczesnych mikroskopów polaryzacyjnych daje możliwość wykonywania zdjęć i bezpośredniego przenoszenia obrazu na ekran oraz do pamięci komputera. Materiałem, z którego może być pobrana próbka do celów archeologicznych, jest ceramika

\footnotetext{
${ }^{7}$ Grubość ziaren w poszczególnych kategoriach to 0,1-2 mm dla frakcji drobnoziarnistej, 2-5 mm dla średnioziarnistej i powyżej 5 mm dla gruboziarnistej (Skalmowski, 1972, s. 34).
} 
naczyniowa, ceramika nienaczyniowa, jak np. cegły, pieczęcie, figurki, fajki i wiele innych artefaktów wykonanych z materiałów litycznych (Quinn, 2013, s. 1, 4, 7, 9).

Należy zaznaczyć, że poza badaniami szlifów cienkich przy pomocy mikroskopu polaryzacyjnego do dyspozycji pozostają metody analizy geochemicznej: instrumentalna neutronowa analiza aktywacyjna (INAA), fluorescencja rentgenowska (XRF), spektrometria mas sprzężona z plazmą wzbudzaną indukcyjnie (ICP-MS) (Quinn, 2013, s. 1). Nie zostały one wykorzystane do materiałów ze stanowisk, które zostały przytoczone $\mathrm{w}$ dalszej części niniejszego artykułu, więc nie istnieje potrzeba tłumaczenia w tym miejscu zasad ich działania. Skupię się zasadniczo na metodach petrograficznych, zastosowanych do artefaktów z okresu neolitu na Kujawach. Metodę szlifów cienkich zastosowano dla stanowiska Wilkostowo 23/24, gm. Aleksandrów Kujawski, woj. kujawsko-pomorskie, które położone jest w północnej części Kujaw, w obrębie środkowego dorzecza Tążyny. Teren ten został zmieniony przez działalność lądolodu w trakcie zlodowacenia Wisły fazy poznańskiej i jego subfazie recesyjnej chodzieskiej. Na stanowisku wystąpiły materiały KPL i KAK, przy czym ceramiki przynależnej do pierwszej z wymienionych kultur było znacznie więcej. Pozyskano między innymi 994 fragmenty ceramiki KAK o łącznej wadze 15028 g (Rzepecki, 2014, s. 11-17). Wskaźnik rozdrobnienia wynosił 0,7 dla ułamków ze stoku i 0,8 dla tych z plateau, w dwóch wyróżnionych skupiskach ceramiki po 0,5 i 0,6 (Rzepecki, 2014, s. 110). Przeprowadzono badania petrograficzne szlifów cienkich pod mikroskopem elektronowym w świetle przechodzącym. Stosowne analizy obejmowały również określenie składu ziarnowego i mineralnego, przez zliczenie poszczególnych składników dla każdej próbki. W ten sposób przebadano m.in. szlify cienkie pobrane z ośmiu fragmentów ceramiki KAK. Trzy z nich charakteryzowały się małą ilością lub nawet brakiem skał magmowych w masie ceramicznej, reszta próbek zawierała ich stosunkowo dużo. W jednej stwierdzono aż 50\% kwarcu. Ze względu na zastosowanie gliny o doskonałej jakości, duża część naczyń pozbawiona była domieszki schudzającej. W przypadku obecności domieszki mineralnej najczęściej rozpoznawano zabieg dodawania okruchów skał magmowych w typie granitów. Domieszka ta została określona jednoznacznie jako celowa, ponieważ poprawiała właściwości produktu końcowego (Pawlikowski, 2014, 509-530).

\section{MAKROSKOPOWE METODY BADAŃ WŁAŚCIWOŚCI TECHNOLOGICZNYCH CERAMIKI KAK}

Niezależnie od badań ceramiki KAK metodami petrograficznymi rozwijał się nurt skupiony na makroskopowej analizie ceramiki neolitycznej, umożliwiającej jej systematykę ze względu na cechy masy ceramicznej. Na tej podstawie stworzono system podziału ceramiki na 4 grupy technologiczne (gt), 3 podgrupy technologiczne (pgt) i 2 elementy grup technologicznych (egt). Całość została skonstruowana na podstawie jasno określonych kryteriów klasyfikacyjnych, tj. rodzaj, grubość i ilość domieszki oraz charakter uwarstwienia przełomu - por. tabela 1. 
Tabela 1. Cechy domieszki ceramiki KAK (za: Szmyt, 1990, ryc. 1).

\begin{tabular}{|c|c|c|c|c|c|c|c|c|c|}
\hline \multirow{3}{*}{$\begin{array}{l}\text { Grupy } \\
\text { czynności } \\
\text { techniczno- } \\
\text {-użytkowych }\end{array}$} & \multirow[b]{3}{*}{ Cechy dystynktywne } & \multirow{3}{*}{\begin{tabular}{l|} 
gt \\
pgt \\
egt
\end{tabular}} & \multirow[t]{3}{*}{ I } & \multirow[t]{3}{*}{ II } & \multicolumn{4}{|l|}{ III } & \multirow[t]{3}{*}{ IV } \\
\hline & & & & & \multirow[t]{2}{*}{$\mathrm{A}$} & \multicolumn{2}{|l|}{ B } & $\mathrm{C}$ & \\
\hline & & & & & & & & & \\
\hline \multirow{4}{*}{$\begin{array}{l}\text { Rodzaj } \\
\text { domieszki }\end{array}$} & Piasek & & 1 & 2 & & 3 & 3 & 3 & 2 \\
\hline & Tłuczeń & & 2 & 2 & 1 & 1 & 1 & 2 & 2 \\
\hline & Tłuczone skorupy & & & 3 & 3 & 3 & 3 & 1 & 3 \\
\hline & Domieszka organiczna & & & 4 & 4 & 4 & 2 & 2 & \\
\hline \multirow{3}{*}{$\begin{array}{l}\text { Granulometria } \\
\text { domieszki }\end{array}$} & Drobna $0,4 \mathrm{~mm}$ & & 1 & 2 & & 2 & 3 & 3 & 2 \\
\hline & Średnia $0,5-0,9 \mathrm{~mm}$ & & 3 & 2 & 3 & 3 & 2 & 3 & 1 \\
\hline & Gruba $1,0-4,0 \mathrm{~mm}$ & & 2 & 3 & 1 & 1 & 1 & 1 & 4 \\
\hline \multirow{3}{*}{ Ilość domieszki } & Mała & & & 2 & 2 & 2 & 2 & & \\
\hline & Średnia & & 2 & 1 & 2 & 2 & 1 & 2 & 3 \\
\hline & Duża & & 1 & 3 & 3 & & 3 & 1 & 1 \\
\hline \multirow{5}{*}{$\begin{array}{l}\text { Charakter } \\
\text { uwarstwienia } \\
\text { przełomu }\end{array}$} & Jednolity & & 1 & 3 & 1 & 1 & 3 & & 1 \\
\hline & Jednolity z tendencją do warwowania & & 3 & 1 & 3 & 3 & 2 & & 3 \\
\hline & Warwowany & & & & & & 1 & & \\
\hline & Silnie warwowany & & & & & & 3 & & \\
\hline & Gruzełkowaty & & & & & & & 1 & \\
\hline
\end{tabular}

Objaśnienie: 1 - cecha dominująca, 2 - cecha występująca wyraźnie, 3 - cecha występująca śladowo, 4 - cecha występująca sporadycznie.

Schemat ten sukcesywnie zastosowano do materiałów ceramicznych pochodzących z wielu stanowisk archeologicznych. Poniżej przedstawię dwa przykłady, w których zastosowano zarówno metody makro-, jak i mikroskopowe.

Aby w pełni ukazać specyfikę ceramiki KAK z Dębów (stan. 29, gm. Dobre, woj. kujawsko-pomorskie), należy przyjrzeć się bliżej położeniu stanowiska i odkrytym w jego obrębie zabytkom (Czebreszuk, Szmyt, 1992, s. 1, 9-13). Stanowisko leży na obszarze Wysoczyzny Kujawskiej, która mimo swej nazwy w rzeczywistości jest terenem charakteryzującym się niewielkimi deniwelacjami, a dokładniej jest położone w obrębie tzw. Piasków Krzywosądzkich. Lokalizacja stanowiska na piaskach eolicznych, stosunkowo bogatych w cieki wodne, wyraźnie odcina się od pozostałej części regionu, gdzie dominują gleby ciężkie, o słabo rozwiniętym systemie hydrograficznym.

Natomiast w odniesieniu do badań nad domieszką ceramiki naczyniowej stwierdzono obecność zarówno tłucznia, jak i miki. Użyty tłuczeń był różnobarwny, a mika występowała w ilościach nieznacznych w niektórych fragmentach ceramiki, zaś w innych było jej więcej. Ten pierwszy stan, tj. obecność różnobarwnego tłucznia, miał być spowodowany nieintencjonalnym dodatkiem do masy ceramicznej, natomiast 
drugi zabieg, związany z obecnością miki, był celowym działaniem pradziejowych garncarzy. Jednak moim zdaniem taki stan również mógł być efektem wybierania różniącego się składem mineralnym materiału skalnego do przygotowania domieszki, zarówno tej o wyższej zawartości miki, jak i takich o znikomym jej udziale. Te różnice zostały odnotowane przez autorów monografii w zestawieniach tabelarycznych, co tworzy jedynie ogólne wyobrażenie o znaczeniu tych cech technologicznych w regułach stosowanych w lokalnym garncarstwie KAK.

W sumie w zbiorze ceramiki naczyniowej KAK ze stanowiska Dęby 29 zdecydowanie dominowała III grupa technologiczna, w różnych wariantach podtypów, rzadsze były grupy II i IV, a do I należał zaledwie pojedynczy fragment (Czebreszuk, Szmyt, 1992, s. 58-88).

Wychodząc od powyższych wyników badań, podjęłam własne i poddałam analizie wybraną ceramikę pochodzącą z zespołu stanowisk Opatowice - Wzgórze Prokopiaka (gm. Radziejów Kujawski, woj. kujawsko-pomorskie), które znajduje się w obrębie Pagórków Radziejowskich należących do Wysoczyzny Kujawskiej (Kośko, Szmyt, 2006, s. 15). Wzgórze zaznacza się wyraźnie na tle moreny radziejowskiej. Od strony północno-wschodniej przylega do niego morena denna, co zwiększa wrażenie wyodrębnienia Opatowic od otaczającego je terenu. Wgląd w sytuację litologiczną interesującej mnie formy terenu dały obserwacje poczynione w obrębie wykopów archeologicznych oraz wyrobisk powstałych po eksploatacji piasku i żwiru. W jej budowie stwierdzono obecność piasków fluwioglacjalnych z pojedynczymi głazikami, których struktura była zaburzona. W niektórych wykopach zarejestrowano glinę morenową lub piaski gliniaste. Teren ten był w całości objęty zlodowaceniem bałtyckim (Nowaczyk, 2006, s. 67-73, 78).

Stanowisko Opatowice 36 położone jest w północnej części Wzgórza Prokopiaka. Jego południowo-wschodnia część została zniszczona w wyniku zaniechanej już eksploatacji piasku, zaś skraj północno-wschodni był wówczas zalesiony. W trakcie pierwszej prospekcji stwierdzono, że stanowisko dość wyraźnie zarysowuje się w terenie, ponieważ zajmuje stoki i kulminację niewielkiego wzniesienia. Uznano, że miało prawdopodobnie charakter osady (Kośko, Szmyt, 2015, s. 15-21). Oprócz przeważających liczebnie reliktów KAK udokumentowano przejawy osadnictwa KPL, interstadium epoki kamienia i brązu, kultury łużyckiej, kultury przeworskiej, wreszcie z okresu wczesnego i późnego średniowiecza oraz z doby nowożytnej. Na stanowisku Opatowice 36 odkryto aż 22927 ułamków naczyń łączonych z KAK o łącznej wadze $149,357 \mathrm{~kg}$. Stanowiły $75,7 \%$ ogółu pozyskanej tam ceramiki, a więc były znakomitą większością zbioru (Szmyt, 2015, s. 99). Był to jednak przypadek odosobniony, ponieważ na innych stanowiskach założonych przez społeczności KAK na Wzgórzu Prokopiaka ceramika tej ludności nie była tak liczna. Całość pozyskanego materiału źródłowego przedstawiała dużą wartość diagnostyczną, co jest fenomenem wśród dotąd opublikowanych stanowisk opatowickich. Zidentyfikowano pięć grup technologicznych. Wśród nich dominowały gt II, pgt IIIA i egt IIIB1, natomiast gt IV i egt IIIB2 stanowiły mniejszość w zbiorze (Szmyt, 2015, s. 216). Na podstawie tych ustaleń oraz szeregu innych przesłanek datujących osadnictwo ludności 
KAK na stanowisku Opatowice 36 zostało przypisane do fazy IIIa wg kujawskiej periodyzacji rozwoju tych społeczności (Szmyt, 2015, s. 222). Dla tego zespołu przeprowadziłam badania mineralogiczno-petrograficzne, którym zostało poddanych 10 fragmentów ceramiki KAK. Wydzielone próbki badałam pod mikroskopem polaryzacyjnym w świetle przechodzącym. Przy pomocy punktowej ilościowej analizy mikroskopowej określony został procentowy udział składników mineralnych obecnych w masie ceramicznej tych naczyń. Wszystkie zawierały ostrokrawędziowe okruchy skał magmowych. Drugą co do udziału domieszką był piasek, jednak nie wystąpił we wszystkich rozpatrywanych próbkach ceramiki, nadto w przypadku części z nich zidentyfikowano wolne przestrzenie po materiale organicznym. Biorąc pod uwagę ogół wymienionych wyżej cech, wydzielono dwa typy zastosowania domieszki mineralnej wśród analizowanej ceramiki naczyniowej KAK (Rauba-Bukowska, 2015, s. 361, 364-366):

- Typ I: Równomiernie rozłożona domieszka w postaci okruchów skał magmowych na tle drobnoziarnistej macierzy, z dużą zawartością najdrobniejszej frakcji. Należy do niego siedem z dziesięciu analizowanych próbek.

- Typ II: Zawiera zarówno domieszkę ostrokrawędziowych okruchów skał magmowych, jak i piasku rozmieszczonych na tle pelitowej macierzy. Ten typ przedstawiają trzy z dziesięciu próbek.

Z kolei stanowisko $\mathrm{nr} 42 \mathrm{w}$ Opatowicach znajduje się w środkowej partii wschodniego stoku Wzgórza Prokopiaka. Zarejestrowano liczny zbiór różnorodnych źródeł ruchomych oraz 103 obiekty nieruchome, w tym pozostałości budowli mieszkalnej, wybierzyska, jamy gospodarcze oraz dołki posłupowe. Pobrano wiele próbek do badań gabinetowych oraz analiz laboratoryjnych. W obrębie zbadanej przestrzeni stanowiska rozpoznano relikty osadnictwa reprezentujące ludność KPL, KAK, interstadium epok neolitu i brązu, kultury łużyckiej, wreszcie wczesnego i późnego średniowiecza oraz ery nowożytnej (Kośko, Szmyt 2007a, s. 13-17). Na rubieży stanowiska udokumentowano obecność pradziejowych wybierzysk różnego rodzaju surowców ${ }^{8}$. Natomiast w południowej i północnej części eksplorowanego terenu odsłonięto kamienny materiał eratyczny w układzie naturalnym (Kośko, Szmyt, 2007b, s. 19-20). Pozyskaną na stanowisku Opatowice 42 ceramikę KAK reprezentowało w sumie 938 fragmentów o łącznej wadze 4023 g. Wystąpiły w ,warstwie” oraz w zasypiskach obiektów łączonych z KPL. Zbiór ten cechował się słabym stanem zachowania, o czym świadczy wysoki wskaźnik rozdrobnienia wynoszący 0,24 . Makroskopową analizą cech technologicznych objęto 693 fragmenty ceramiki. Ustalono w ten sposób, że większość z nich reprezentuje gt III, opartą na domieszce gruboziarnistego thucznia kamiennego. Nie stwierdzono natomiast gt I, a gt II i IV oraz egt IIIC wystąpiły w mniejszości (Szmyt, 2007, s. 255). Na tej podstawie ustalono, że udokumentowane na stanowisku Opatowice 42 przejawy osadnictwa ludności KAK należy

\footnotetext{
${ }^{8}$ Stwierdzono ślady pradziejowej działalności po eksploatacji piasku, kamieni oraz silnie spiaszczonej gliny.
} 
sytuować w ramach klasycznego etapu rozwoju kujawskich ugrupowań, tj. w ramach faz IIb-IIIa (Szmyt, 2007, s. 273).

Stanowisko 3 w Kruszy Zamkowej (gm. Inowrocław, woj. kujawsko-pomorskie) do tej pory nie doczekało się osobnej, wyczerpującej publikacji monograficznej. Pojawia się jedynie w pracach kompilacyjnych, głównie w formie wspomnienia o jego istnieniu, bez podania większej ilości danych (por. Czerniak, Czerniak, 1984). Jednak to właśnie źródła ceramiczne z obiektu nr 295, odkryte na stanowisku Krusza Zamkowa 3, dały (wraz z materiałami z innych stanowisk kujawskiej KAK) podstawę do stworzenia schematu systematyki cech technologicznych garncarstwa społeczności KAK w rejonie Kujaw (Czerniak, Czerniak, 1984). Należy przypomnieć, że w pierwotnej propozycji nie istniały jeszcze - wyróżnione później - gt IV, pgt IIIC oraz egt IIIB1 i IIIB2. Z interesującego mnie obiektu 295 z Kruszy Zamkowej ocenie cech technologicznych poddano 150 fragmentów ceramiki naczyniowej KAK o łącznej wadze $6818 \mathrm{~g}$ i wskaźniku rozdrobnienia 0,028 . Spośród analizowanych ułamków naczyń blisko $10 \%$ sklasyfikowano jako gt II, 26\% - gt I, 57,6 \% - egt IIIA1, 5,8\% - egt IIIA2, a 0,3\% - pgt IIIB (Czerniak, Czerniak, 1984, s. 34-38). Dotychczasowe rozważania stały się podstawą próby odtworzenia procesu wytwórczego ceramiki w zakresie przygotowania masy ceramicznej.

\section{PRÓBA EKSPERYMENTALNEGO ODTWORZENIA PROCESU WYTWARZANIA DOMIESZKI ZE SKAL GRANITOWYCH W KAK NA KUJAWACH}

Na podstawie przedstawionych we wcześniejszych częściach artykułu informacji dotyczących szeroko rozumianego aspektu zastosowań domieszki mineralnej w garncarstwie późnoneolitycznych społeczności KAK w rejonie Kujaw, opracowałam eksperyment naukowy ujawniający praktyczne możliwości oraz sposoby pozyskiwania tłucznia granitowego spośród dostępnych lokalnie skał narzutowych. Jego głównym celem było rozpoznanie dokładniejszego charakteru uziarnienia eratyków granitu, z których potencjalnie mogła być pozyskiwana właściwa domieszka oraz możliwe stawało się określenie wpływu rozprężenia termicznego na trwałość materiału skalnego'. Wbrew pierwotnym zamierzeniom nie mogłam posłużyć się jakimkolwiek profesjonalnym sprzętem do precyzyjnego pomiaru wyników doświadczenia. $Z$ tych powodów przebieg eksperymentu oraz jego wyniki mogą zostać opisane jedynie przez pryzmat moich obserwacji. Wprawdzie fakt ów umniejsza, co zrozumiałe, (choć w moim przekonaniu nieznacznie) wartość naukową pracy i utrudnia wykonanie ewentualnych eksperymentów porównawczych, to jednak uważam, że osiągnięte efekty są rzetelne i wiarygodne, a sam przebieg warunków doświadczenia powtarzalny.

\footnotetext{
${ }^{9}$ Ten aspekt został przetestowany poprzez wygrzewanie kamieni w ognisku, a następnie gwałtownym schładzaniu kamieni przez wrzucenie ich do zimnej wody.
} 
Niniejsza część pracy prezentuje dokładny opis przebiegu całego eksperymentu, wraz $\mathrm{z}$ wyprowadzonymi z niego wnioskami.

Do eksperymentu wyselekcjonowałam dziesięć skał sklasyfikowanych pod względem petrograficznym jako granity. Wydzieliłam bloki skalne o różnym stopniu uziarnienia, od średnioziarnistych na drobnoziarnistym tle, po konkrecje, które posiadały ziarna (minerały) dobrze wykształcone i relatywnie większych rozmiarów. Tylko jedna z próbek o $\mathrm{nr} 10$ była fragmentem większej, rozbitej uprzednio bryły granitu. Pozostałe reprezentowały naturalne, nieprzekształcone formy konkrecji kamiennej. Granity przeznaczone do eksperymentu pozyskałam z dwóch różnych miejsc położonych w obrębie Pojezierza Wielkopolsko-Kujawskiego. Pierwsze z nich zlokalizowane jest na Kujawach - w okolicach Kruszy Zamkowej, gm. Inowrocław, woj. kujawsko-pomorskie. Drugie natomiast w Wielkopolsce - nieopodal Jeziora Tomickiego, w gm. Stęszew, woj. wielkopolskie. Tereny, skąd pobrałam granitowe głaziki, leżą więc w zasięgu ostatniego zlodowacenia plejstoceńskiego, na których dostęp do eratycznego surowca kamiennego był powszechny.

Wszystkie użyte do eksperymentu skały reprezentują granitowe eratyki fennoskandzkie, najczęściej występujące w polodowcowym rezerwuarze skał narzutowych (Chachlikowski, 2013). Zdecydowałam się na wybór okazów o stosunkowo niewielkich rozmiarach, z powodów czysto praktycznych. Większe egzemplarze byłyby trudne w obróbce i transporcie na większe odległości. Do części eksperymentu, która obejmowała termiczne rozprężanie struktury granitu, użyłam $10 \mathrm{~kg}$ węgla drzewnego, $5 \mathrm{~kg}$ brykietów drzewnych i sporej ilości suchych gałęzi jako materiału opałowego. Dodatkowo wykorzystałam do tego łopatki, graczki i szczypce, które posłużyły mi do przekładania kamieni z paleniska do naczyń z zimną wodą. Użyłam również dwóch garnków emaliowanych na zimną wodę. Natomiast w drugiej części doświadczenia, w ramach której przekształcałam mechanicznie próbki na domieszkę (poprzez uderzanie), użyłam granitowego kamienia jako podkładki oraz tłuka z tego samego materiału skalnego.

Część pierwsza zaczęła się od wyboru miejsca, w którym można było rozpalić ognisko. Za najdogodniejsze do planowanego przedsięwzięcia uznałam polanę przy Źródełku Żarnowiec, usytuowane w okolicy wspomnianego już wyżej Jeziora Tomickiego. Zadecydowały przygotowane tam miejsca do palenia ognia oraz bezpośredni dostęp do wody. Następnie uszykowałam i rozpaliłam ognisko, do którego dokładałam opał w taki sposób, aby utrzymać w miarę stałą temperaturę przez czas trwania tej części doświadczenia. Wygrzewanie kamieni wydzielonych do eksperymentu było podzielone na pięć cykli o zbliżonym przebiegu. W trakcie każdego z nich skały były umieszczane w najgorętszym miejscu ogniska, a po upływie dwudziestu minut wyjmowane i każdorazowo umieszczane w naczyniach z zimną wodą. Powtórzono ten

${ }^{10}$ Próbka nr 5 jako jedyna była wcześniej oddzielona od większej konkrecji skalnej. W jej przypadku proces pozyskiwania domieszki wydłuża się o jedną czynność, jaką była wstępna obróbka mechaniczna. Jak już wspomniałam takie małe odłupki skalne mogły być też efektem ubocznym w procesie wytwarzania narzędzi metodą przekształcenia morfometrycznego. 
zabieg pięć razy. Wynika stąd, że każda bryła przebywała w ogniu przez 100 minut. Dzięki temu chciałam uzyskać efekt rozprężenia się minerałów w wybranych przeze mnie próbach skał granitu. Po zakończeniu pierwszego etapu przystąpiono do realizacji drugiego, który polegał na wstępnym rozbiciu wszystkich próbek, a w przypadku powodzenia tej akcji również na rozdrobnieniu do postaci domieszki identycznej z pradziejową recepturą. Próbki skał były fotografowane, jednak jakość zdjęć nie nadaje się do druku, dlatego pozostanę przy ich opisie. Próbka nr 1 była małą konkrecją skalną, miała duże, stopione z sobą ziarna. Poddawała się rozbiciu z trudem, niestety nie zdołano uzyskać frakcji nadającej się na domieszkę mineralną. Próbka nr 2 była konkrecją podobnie o niewielkich gabarytach, o drobnych ziarnach, zatopionych w umiarkowanie jednolitej macierzy skalnej. Nie poddała się próbie rozbicia. Próbka nr 3 była także małych rozmiarów, o grubych, dobrze wykształconych ziarnach. Uległa rozbiciu i rozdrobnieniu przy użyciu małej siły uderzenia. Podobną strukturę posiadała próbka $\mathrm{nr} 4$, która równie łatwo poddała się obróbce mechanicznej. Z kolei próbka $\mathrm{nr} 5$, w przeciwieństwie do pozostałych, była wcześniej oddzielona przeze mnie od większego bloku skalnego. Miała duże, dobrze wykrystalizowane minerały budujące skałę. Także i ona bardzo łatwo, a nawet - w porównaniu z wszystkimi pozostałymi naturalnymi bryłami granitu (tzw. surowiakami) - najłatwiej poddała się rozbiciu i rozdrobnieniu. Był to granit rapakiwi. Próbka nr 6 była średniej wielkości konkrecją, z żelazistymi wtrętami. Trudno ją było rozbić, ze względu na warstwę korową, lecz tak pozyskane fragmenty łatwo uległy rozdrobnieniu. Natomiast próbka nr 7 była małym gruboziarnistym surowiakiem, o dobrze wykrystalizowanej strukturze. Łatwo uległa obróbce mechanicznej. Próbka nr 8 była średniej wielkości bryłą granitu, mieszaniną dość dobrze stopionych ze sobą średnich i grubych ziaren. Łatwo uległa rozbiciu, ale trudno było pozyskać z niej frakcje nadające się na domieszkę. Próbka nr 9 była kolejną konkrecją skalną niewielkich rozmiarów, o średniej wielkości ziarnach, dobrze stopionych z tłem skalnym. Nie poddała się obróbce mechanicznej. Wreszcie próbka nr 10 była podobnie nieznacznych gabarytów oraz o średnich, dobrze wykształconych ziarnach. Uległa rozbiciu i rozdrobnieniu przy użyciu stosunkowo małej siły.

\section{PODSUMOWANIE}

Wnioski, jakie można sformułować na temat domieszki w ceramice KAK na Kujawach, wskazują na znaczącą pozycję kamienia, głównie tłucznia granitowego jako domieszki schudzającej, używanej do wyrobu ceramiki naczyniowej. Przedstawiciele sąsiednich ugrupowań kulturowych, jakimi byli członkowie społeczności KPL, dla których materiał skalny odgrywał również niepoślednią rolę, używały jednak innych domieszek w garncarstwie (jak np. piasek, thuczone skorupy czy rozdrobnione muszle). Dziś nie jesteśmy w stanie dokładnie określić, co konkretnie skłaniało przedstawicieli społeczności KAK do podjęcia tak pracochłonnej czynności, jaką było pozyskanie domieszki z kamieni w typie granitów, tym bardziej że pod ręką powszechnie 
dostępny był także piasek, niewymagający przecież dodatkowych zabiegów technicznych. Zabieg dodawania do gliny wytwarzanych, relatywnie dużych, ostrokrawędzistych okruchów skalnych zmieniał właściwości techniczne naczyń. Trudno wytłumaczyć tak nagłą popularność, wręcz powszechność takiej domieszki schudzającej tylko i wyłącznie możliwością budowania większych naczyń oraz mniejszą szansą uszkodzenia $\mathrm{w}$ trakcie procesu wytwarzania ceramiki. W moim przekonaniu musiało to być waloryzowane kulturowo (chociaż w minimalnym stopniu) na gruncie tradycji, a być może nawet, co nie jest takie niemożliwe, determinowane specyfiką kultury, w której ,splątane” były wszystkie jej elementy. Warto bowiem w tym miejscu zwrócić uwagę na obserwacje kolorystyki wykorzystywanej przez ludność kultury amfor kulistych domieszki granitowej, a konkretnie minerałów barwy czerwonej, która, jak wiemy, jest powszechnie obecna, a niekiedy także dominuje w domieszkach w późnoneolitycznym garncarstwie tych społeczności. Należy także podkreślić, że najlepiej nadające się do tego celu kamienie są bardzo atrakcyjne pod względem wizualnym (estetycznym).

Podsumowując ogół wniosków z przeprowadzonego eksperymentu, należy zwrócić uwagę na pewne niedociągnięcia, zwłaszcza wydzielone do niego próby skał o zbyt małych rozmiarach. Również sam proces nagrzewania przebiegł zbyt krótko (mimo jego pięciokrotnego powtórzenia), aby poddane doświadczeniu bloki granitu uległy odpowiednio wysokiemu naprężeniu, umożliwiającemu jego rozkruszenie, a tym samym pozyskanie pożądanej domieszki mineralnej. Nadto, jak wykazało doświadczenie, nie każdy granit odpowiada strukturą mineralną, podobnie wielkością ziaren, domieszce stosowanej przez społeczności KAK do wytwarzania ceramiki naczyniowej. Mimo sygnalizowanych wyżej trudności, doświadczenie zdobyte przeze mnie na tym etapie eksperymentu może stanowić wartościowy punkt wyjścia dla kontynuacji badań nad zagadnieniem pozyskiwania domieszki tłucznia kamiennego przez ludność KAK na Niżu Polskim, tym razem już przy zachowaniu w pełni rygorów powyższego eksperymentu.

Na drodze doświadczalnej wykazałam, że w najwyższym stopniu rozdrobnieniu poddają się konkrecje granitu o grubych, ostrokrawędziowych minerałach. Muszą jednak podlegać dłuższej, jednorazowej obróbce termicznej (zapewne wymagającej dłuższego czasu ekspozycji na wysoką temperaturę, możliwej przy całodziennym i codziennym użytkowaniu paleniska). Z pewnością przy zachowaniu takich warunków eksperymentu znacznie łatwiej i również prostszym sposobem można pozyskać odpowiednią domieszkę. Świadczą o tym m.in. obserwacje poczynione w trakcie eksperymentu dotyczące próbki nr 5 - granitu rapakiwi, a które jednoznacznie przekonują, że najłatwiej przetworzeniu, a co za tym idzie rozkruszeniu uległ fragment, który był oddzielony wcześniej od konkrecji o dużych rozmiarach. Mogły to być pozostałości po wytwarzaniu narzędzi metodą przekształcenia morfometrycznego. Jest to tym bardziej prawdopodobne, że w okresie standardowego stosowania domieszki granitowej przez ludność KAK wytwarzanie narzędzi przy użyciu techniki przekształcenia morfometrycznego w odniesieniu do wyrobów wykonywanych z tej skały było relatywnie powszechne (Chachlikowski, 1990, s. 223-255, 262-265). 
Należy wyraźnie podkreślić, że mimo sygnalizowanych ograniczeń, niewątpliwym osiągnięciem przeprowadzonego przeze mnie eksperymentu jest stwierdzenie, że domieszka granitowa, którą uzyskałam w wyniku doświadczenia, jest porównywalna $\mathrm{z}$ tą, którą zaobserwowałam w próbkach ceramiki KAK pochodzącej z kilku stanowisk położonych w rejonie Kujaw (Krusza Zamkowa, stan. 3; Tarkowo, stan. 61, 75 oraz Opatowice, stan. 3, 24, 33, 36). Oznacza to, że dostępne na miejscu granity fennoskandzkie pochodzenia lodowcowego stanowiły naturalne źródło tego surowca i były z powodzeniem wykorzystywane jako materiał skalny niezbędny do pozyskiwania „odkrytej” i poszukiwanej domieszki przez ówczesnych garncarzy.

\section{BIBLIOGRAFIA}

Chachlikowski, P.

1990 Stan badań nad kamieniarstwem społeczności kultury amfor kulistych na Kujawach. W: A. Cofta-Broniewska (red.), Kultura amfor kulistych w rejonie Kujaw (s. 225-274). Poznań: Wydawnictwo Uniwersytetu Adama Mickiewicza.

1994 Późnoneolityczne wybierzysko surowców skał niekrzemiennych w miejscowości Goszczewo, gm. Aleksandrów Kujawski, woj. Włocławek, stanowisko 13. Folia Praehistorica Posnaniensia, 6, 59-121.

2013 Surowce eratyczne w kamieniarstwie spoleczeństw wczesnoagrarnych Niżu Polskiego (IV-III tys. przed Chr.). Poznań: Garmond.

Cofta-Broniewska, A. (red.)

1990 Kultura amfor kulistych w rejonie Kujaw. Poznań: Wydawnictwo Uniwersytetu Adama Mickiewicza.

Czebreszuk, J.

1996 Społeczności Kujaw w początkach epoki brąu. Poznań: Poznański Serwis Oświatowy.

Czebreszuk, J., Szmyt, M.

1992 Osadnictwo neolityczne i wczesnobrazowe w Dębach woj. włocławskie, stanowisko 29. Poznań: Wydawnictwo Uniwersytetu Adama Mickiewicza.

Czekalska, A., Kunkel, A.

1977 Mineralogia i petrografia dla geografów. Warszawa: PWN.

Czerniak, E., Czerniak, L.

1984 Z badań nad genezą i rozwojem kultury amfor kulistych na Kujawach. Folia Praehistorica Posnaniensia, 1, 23-55.

Czubla, P., Papińska, E.

2006 Geografia fizyczna. Warszawa: PWN.

Galon, R. (red.)

1972 Geomorfologia Polski, t. 2: Niż Polski. Warszawa: PWN.

Górska, M.

2000 Wybrane wtaściwości vistuliańskich moren dennych środkowej i zachodniej Wielkopolski oraz ich znaczenie dla oceny dynamiki ostatniego ladolodu. Poznań: Wydawnictwo Po-

Kośko, A., Szmyt, M.

znańskiego Towarzystwa Przyjaciół Nauk.

2006 Historia, problematyka i metodyka badań archeologicznych na Wzgórzu Prokopiaka w Opatowicach. W: A. Kośko, M. Szmyt, Opatowice - Wzgórze Prokopiaka, t. 1 (s. 1526). Poznań: Wydawnictwo Poznańskie. 
2007a Przebieg badań. W: A. Kośko, M. Szmyt, Opatowice - Wzgórze Prokopiaka, t. 3 (s. $13-$ 18). Poznań: Wydawnictwo Poznańskie.

2007 b Charakterystyka jednostek stratygraficzno-kulturowych. W: A. Kośko, M. Szmyt, Opatowice - Wzgórze Prokopiaka, t. 3 (s. 19-52). Poznań: Wydawnictwo Poznańskie.

Lorenc, W. M., Mazurek, S.

2007 Wykorzystać kamień. Wrocław: Studio JASA.

Marcinek, J.

$1991 \quad$ Lodowce kuli ziemskiej. Warszawa: PWN.

Nowaczyk, B.

2006 Eoliczne piaski pokrywowe na Wzgórzu Prokopiaka w Opatowicach koło Radziejowa Kujawskiego. W: A. Kośko, M. Szmyt, Opatowice - Wzgórze Prokopiaka, t. 3 (s. 67-80). Poznań: Wydawnictwo Poznańskie.

Pawlikowski, M.

2014 Wyniki badań mineralogicznych i technicznych ceramiki i polepy. W: S. Rzepecki (red.), Wilkostowo 23/24. Neolityczny kompleks osadniczy, t. 1 (s. 509-530). Łódź: Wydawnictwo Instytut Archeologii Uniwersytetu Łódzkiego.

Prinke, A., Skoczylas, J.

$1980 \quad$ Neolityczne surowce kamienne w Polsce środkowo-zachodniej. Warszawa: PWN.

Quinn, P. S.

2013 Ceramic petrography. The interpretation of archaeological pottery and related artefacts in thin section. Oxford: Archaeopress.

Rauba-Bukowska, A.

2015 Mineralogiczno-petrograficzna charakterystyka ceramiki i polepy. W: A. Kośko, M. Szmyt, Opatowice - Wzgórze Prokopiaka, t. 5 (s. 361-374). Poznań: Wydawnictwo Uniwersytetu Adama Mickiewicza.

Rzepecki, S. (red.)

2014 Wilkostowo 23/24. Neolityczny kompleks osadniczy, t. 1. Łódź: Wydawnictwo Instytutu Archeologii Uniwersytetu Łódzkiego.

Skalmowski, W.

1972 Technologia materiałów budowlanych, t. 1. Warszawa: Arkady.

Szmyt, M.

1990 Stan badań nad zasadami analityki kultury amfor kulistych. W: A. Cofta-Broniewska (red.), Kultura amfor kulistych w rejonie Kujaw (s. 79-86). Poznań: Wydawnictwo Uniwersytetu Adama Mickiewicza.

1996 Społeczności kultury amfor kulistych na Kujawach. Poznań: Poznański Serwis Oświatowy.

2007 Ceramika kultury amfor kulistych. W: A. Kośko, M. Szmyt, Opatowice-Wzgórze Prokopiaka, t. 3 (s. 255-294). Poznań: Wydawnictwo Poznańskie.

2013 Late neolithic landscapes on the Polish Lowland: People, culture and economy in Kujawy $-4^{\text {th }}$ and $3^{\text {rd }}$ millennia BC. Poznań: Wydawnictwo Uniwersytetu Adama Mickiewicza.

2015 Rejestr źródeł ruchomych, kulturowych i przyrodniczych. W: A. Kośko, M. Szmyt, Opatowice - Wzgórze Prokopiaka, t. 5 (s. 99-118). Poznań: Wydawnictwo Uniwersytetu Adama Mickiewicza.

Świerczyńska, A. M.

2018 Pozyskiwanie domieszki mineralnej w garncarstwie ludności kultury amfor kulistych na Kujawach (niepublikowana praca licencjacka). Wydział Historyczny Uniwersytetu Adama Mickiewicza . 


\title{
THE STUDIES ON THE MINERAL ADMIXTURE IN THE CERAMIC VESSELS OF THE GLOBULAR AMPHORA CULTURE FROM THE KUYAVIA REGION
}

\author{
S u m m a r y
}

The purpose of this study was to acquire clay inclusions made from granites. More precisely, in the whole academic literature, they are called mineral inclusions, but only granites fulfill the criteria. This phenomenon is associated with the neolithic Globular Amphora Culture, especially in the classical phase (IIb-IIIa), in the Kuyavia region. Erratic raw materials dominate local stone resources. They were carried by the glacier. However, there are plenty of igneous, plutonic rocks called granites in archeological terminology. The history of researches is also included in the article: most important techniques for recognizing inclusions in clay, a brief history of studies on the usage of inclusions, which were used in the production of ceramic in prehistory, and selected sites where inclusion was examined. The following part covers my study of the production of inclusions. I aimed to find a type of granite with the best processing properties. For this purpose, I chose ten samples of granites. I determined that the alandish granite rapakivi has the best processing properties. Those granites consist of large crystals, which are nearly identical to inclusions present in prehistorical ceramic. Results, which confirm the thesis, are presented in summary. 